\title{
Percutaneous Left Main Coronary Intervention: A Review of Plaque Modification in Left Main Percutaneous Coronary Intervention
}

\author{
Chirag A. Shah ${ }^{1, *}$ and Steven E. Pfau ${ }^{1,2, *}$ \\ 1 Yale-New Haven Hospital, Yale School of Medicine, New Haven, CT 06510, USA \\ 2 West Haven Veterans Administration Hospital, West Haven, CT 06516, USA \\ * Correspondence: chirag.shah@yale.edu (C.A.S.); steven.pfau@yale.edu (S.E.P.)
}

Received: 1 July 2018; Accepted: 20 July 2018; Published: 23 July 2018

\begin{abstract}
Left main coronary artery (LMCA) stenosis has long been recognized as a marker of increased morbidity and mortality. Current treatment algorithms for LMCA stenosis consider both percutaneous coronary intervention (PCI) with drug eluting stents (DES) and coronary bypass surgery, each with advantages based on individual patient characteristics. Since the LMCA is the largest artery in the coronary tree, plaque volume and calcification is greater than other coronary segments and often extends to the distal bifurcation segment. In LMCA bifurcation lesions, larger minimal stent area is strongly associated with better outcome in the DES era. Plaque modification strategies such as rotational, orbital, or laser atherectomy are effective mechanisms to reduce plaque volume and alter compliance, facilitating stent delivery and stent expansion. We present a case of a calcified, medina class 1,1,1 LMCA lesion where intravascular ultrasound (IVUS) and orbital atherectomy were employed for optimal results. In this context, we review the evidence of plaque modification devices and the rationale for their use in unprotected left main PCI.
\end{abstract}

Keywords: left main coronary artery; left main percutaneous coronary intervention; coronary artery bypass surgery; atherectomy; percutaneous coronary intervention

\section{Introduction}

Stenosis of the left main coronary artery (LMCA) is associated with increased morbidity and mortality in patients with coronary artery disease, when compared to elsewhere in the coronary tree [1]. Initial experiences with percutaneous treatment, including Grüntzig's third patient, were associated with excess complications and mortality; as a result, surgical revascularization became firmly established as the standard of care [2]. With experience, improved stent technology, and important randomized trials, outcomes of percutaneous coronary intervention (PCI) with second generation drug-eluting stents (DES) may be similar to surgery in many patients, and PCI is the preferred strategy in patients with increased surgical risk [3-10]. Due to the size of the left main, plaque formation in the LMCA has a more disseminated distribution, higher plaque volumes, and an increased presence of severe calcification $[11,12]$ when compared to lesions elsewhere in the coronary tree. Angioplasty and stenting for left main bifurcation stenosis, the most frequent phenotype of left main disease, therefore has important technical considerations compared to interventions in other coronary lesions. Intravascular ultrasound (IVUS) has contributed significantly to the understanding of procedural success in left main PCI, including that larger stent area is a significant predictor of improved long-term outcome, even in the DES era [13]. Atherectomy, using rotational, orbital, or laser devices is recognized as an effective mechanism for modification of plaque that can facilitate stent delivery and expansion, particularly in calcified lesions [14-17]. Application of debulking/plaque modification strategies may 
be particularly relevant in unprotected left main (UPLM) PCI where plaque volume is high, significant calcification is frequent, and final stent area is critical [11,12]. These considerations are particularly relevant as overlapping and stent crushing strategies are emerging as superior to single stent strategies in true bifurcation lesions $[5,18]$. Here we review the evidence for plaque modification strategies and the rationale for their more routine use in left main PCI.

\section{Left Main PCI}

A 79-year-old male presented for an elective coronary angiogram for Canadian Cardiovascular Society Class 3 angina and progressive dyspnea on exertion. Medical history was complex and included atrial fibrillation, insulin dependent diabetes, dual chamber pacemaker, prostate cancer, moderately differentiated adenocarcinoma of the ascending colon with a recent hemicolectomy, and heart failure with preserved ejection fraction. On coronary angiogram (Figure 1), he was found to have $80 \%$ distal LMCA stenosis extending to the left anterior descending (LAD) artery and Circumflex (CFX) artery (Medina 1.1.1), with moderate calcification. The right coronary was chronically occluded; the SYNTAX score was 42. A transthoracic echocardiogram revealed a preserved left ventricular ejection fraction of $55 \%$ and moderate aortic stenosis (peak velocity of $2.8 \mathrm{~m} / \mathrm{s}$, mean gradient of $18 \mathrm{mmHg}$, and calculated aortic valve area of $1.0 \mathrm{~cm}^{2}$ ). Cardiac surgery was consulted for coronary artery bypass surgery and aortic valve replacement, but he was deemed high risk for surgery due to a Society of Thoracic Surgery score of $11.6 \%$ and a heavily calcified ascending aorta. Following a Heart Team discussion, the decision was made to proceed with UPLM PCI.

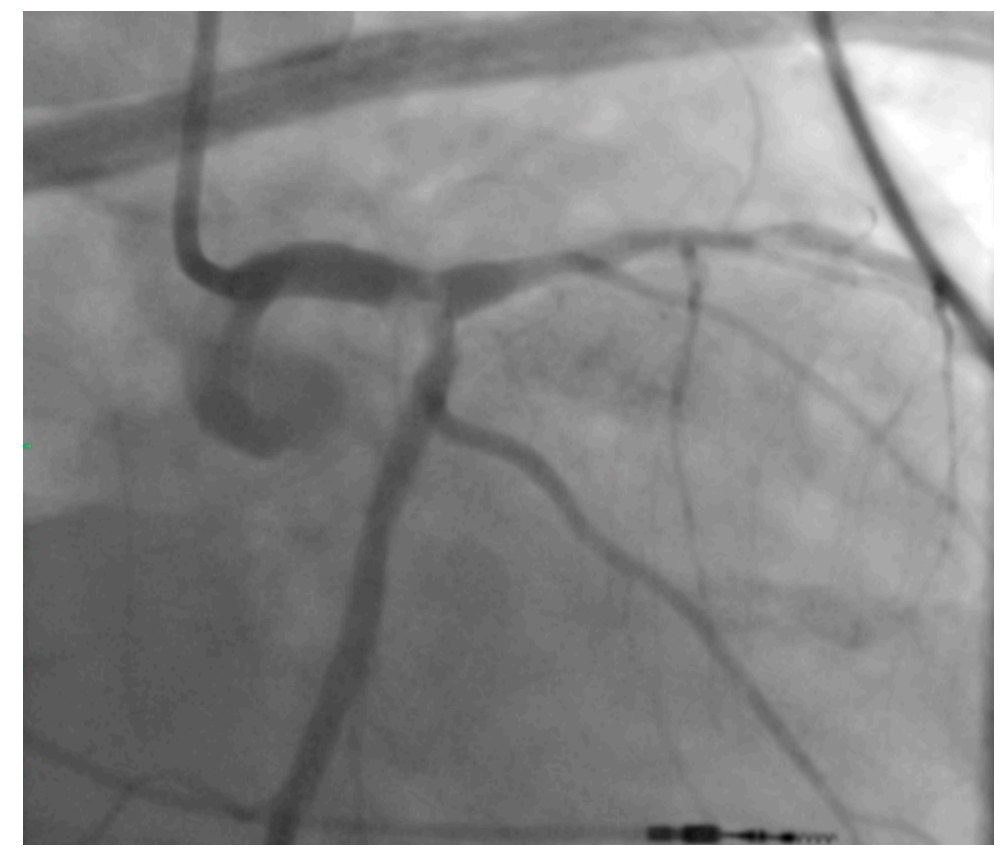

Figure 1. Pre-Intervention Coronary Angiogram. There is evidence of a calcific $80 \%$ distal left main coronary artery lesion that extends to the left anterior descending and left circumflex arteries (Medina 1.1.1).

Left main coronary artery disease is a complex disease process that is associated with increased morbidity and mortality due to the extent of myocardium that is at risk for ischemia $[1,5,19,20]$. For most patients with left main coronary artery disease, American College of Cardiology / American Heart Association practice guidelines recommend coronary artery bypass surgery (CABG) as the preferred mode of revascularization [21]. Contemporary randomized trials, however, suggest clinical equipoise for PCI and CABG in select patient populations $[3,7,8,22,23]$ Five-year outcomes from the SYNTAX trial show that PCI for UPLM with a SYNTAX score $<33$ had similar rates of death, myocardial 
infarction, or stroke when compared to CABG [22], even though this trial utilized early generation DES. More recently, the EXCEL trial randomized 1905 subjects to PCI with a second-generation DES or CABG for UPLM stenosis with a low or intermediate SYNTAX score. In EXCEL, UPLM PCI with a SYNTAX score $<33$ was noninferior to CABG with respect to death, MI, or stroke at 3 years $(15.4 \%$ for PCI versus $14.7 \%$ for CABG) [3]. Further, there was no difference in the Seattle Angina Questionnaire score at 1 year or 3 years [4]. The contemporaneous NOBLE trial randomized 1201 patients to either PCI (also with second generation DES) or CABG for LMCA stenosis with an intermediate SYNTAX score. In this study, CABG was superior to PCI with regards to MACCE at 5 years ( $28 \%$ for PCI and $18 \%$ for CABG, HR 1.51 with $95 \%$ CI 1.13-2.00 with a $p$-value of 0.0044 ) [23]. A recent meta-analysis, which examined 4499 subjects from 5 randomized studies (EXCEL, NOBLE, LE MANS, SYNTAX, and PRECOMBAT) suggested no difference between PCI and CABG for the treatment of UPLM disease for the composite endpoints of death, stroke, and MI (OR of 1.03, 95\% CI 0.81-1.32, p-value of 0.81) [24]. While these trials enrolled patients with acceptable surgical risk, in patients with excess surgical risk, such as the case presented here, clearly UPLM PCI would be the preferred revascularization strategy.

\section{Technical Considerations: The Role of Intravascular Ultrasound in UPLM PCI}

Utilization of intracoronary imaging in PCI (particularly IVUS) has provided insights into coronary anatomy, plaque distribution and content, and mechanisms of PCI success and failure. This information has helped to select treatment strategies, and define optimal final stent diameter/area associated with improved PCI outcomes in the bare metal stent and DES eras [25-27]. In left main PCI, pre-procedural IVUS is critical for determining the severity of disease in both the proximal LAD artery and the proximal CFX artery $[3,26,28]$; the distribution of plaque in each branch will help to determine which will be the parent vessel (most commonly the LAD) and whether a single stent can be used. Angiography often underestimates calcification, and pre-intervention imaging can be an important tool to document whether calcification may be a factor in limiting complete stent expansion $[28,29]$. Additional information includes the distal reference vessel diameter and the length of stent that is required. Following stent deployment, IVUS is important to assure adequate stent expansion. In UPLM PCI, IVUS determined stent minimal lumen area (MLA) targets in the proximal LAD $\left(6 \mathrm{~mm}^{2}\right)$, proximal CFX $\left(5 \mathrm{~mm}^{2}\right)$, and distal LM $\left(8 \mathrm{~mm}^{2}\right)$ have been associated with the best short and intermediate term outcomes [13]. Published data regarding IVUS guidance in PCI for UPLM lesions is consistent in terms of improved mortality, rates of stent thrombosis, and event free survival when compared to LMCA revascularization without IVUS in the DES era [26,27,30]. In MAIN-COMPARE, IVUS guided UPLM PCI was associated with a $60 \%$ lower 3-year mortality rate when compared to angiographic guidance [27]. IVUS-guided PCI of the LMCA results in lower incidence of stent underexpansion, thus lower rates of in-stent restenosis (ISR) and target lesion revascularization (TLR) [30]. In this context, IVUS guidance has become standard practice for this lesion subset; approximately $80 \%$ of procedures in the EXCEL trial incorporated IVUS as an adjunctive tool [3].

The left coronary was engaged with an 8Fr extra-back up (EBU) 3.75 guide. By angiography, the LMCA was moderately calcified with extension of the calcium into the proximal LAD and CFX. Given the severity of the stenosis, obvious calcification, and right coronary artery CTO, a preintervention IVUS was deferred. The LMCA and LAD lesions were primarily wired with an orbital atherectomy guidewire. Orbital atherectomy was performed of the LMCA and proximal LAD using an orbital atherectomy catheter. One pass was made at 80,000 RPM (1.25 mm orbit), with 2 subsequent passes made at 120,000 RPM (3.0 mm orbit). Following atherectomy, IVUS was performed using a $40 \mathrm{MHz}$ imaging catheter, revealing a 270-degree arc of calcium in the distal LMCA (Figure 2) with an MLA of $7.7 \mathrm{~mm}^{2}$. At this point, the CFX lesion was crossed using an $0.014 \mathrm{~mm}$ coronary guidewire. A $40 \mathrm{MHz}$ IVUS was then used to interrogate the CFX, revealing 35 degrees of dense calcification. Given the relative limited extent of calcification, atherectomy was not performed in the CFX. 


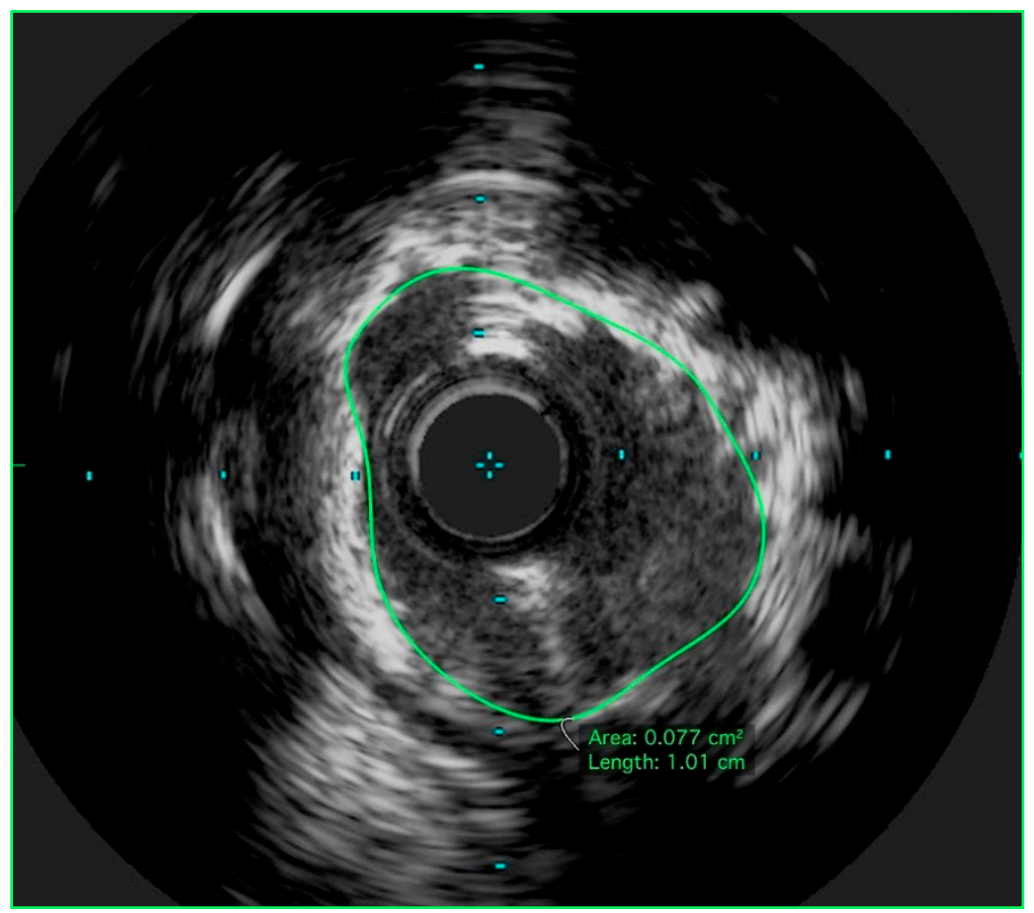

Figure 2. Post-orbital atherectomy IVUS of LMCA. IVUS of the LMCA with a $40 \mathrm{MHz}$ imaging catheter performed after orbital atherectomy revealing 270 degrees of calcium and a minimal luminal area of $7.7 \mathrm{~mm}^{2}$. IVUS: Intravascular ultrasound; LMCA: Left main coronary artery.

\section{Achieving Adequate Left Main Minimal Luminal Area}

While stent area by IVUS is associated with improved short and long term outcome in the bare metal stent era [31,32], that association has been lost with the routine use of DES. Only a single randomized study (IVUS XPL) has been able to show a benefit from IVUS guided stent optimization of DES, specifically in long (greater than $28 \mathrm{~mm}$ ) and small (less than $2.5 \mathrm{~mm}$ diameter) artery segments [33]. Although there are no randomized data, routine use of IVUS has been associated with improved outcome in UPLM PCI, and adequate stent expansion is one mechanism by which routine IVUS accomplishes this difference. In registry data, stent underexpansion with current generation DES is an independent predictor of 2-year major adverse cardiac events (MACE) and TLR [13,29]. In contrast, acute stent malapposition in UPLM PCI was not related to ISR or MACE [13]. The group at Asan Medical Center in Seoul, Korea has provided the most systematic analysis of the LMCA IVUS information. For the purposes of their retrospective outcomes study, the LMCA is divided into 4 segments: (1) the ostial left circumflex artery (5 mm distal to the carina); (2) the ostial left anterior descending artery ( $5 \mathrm{~mm}$ distal to the carina); (3) the polygon of confluence (POC, the confluence zone of the LAD and LCx on longitudinal IVUS image reconstruction); and (4) the proximal left main segment (just above the POC) [13]. In UPLM PCI, a smaller IVUS-derived minimal stent area (MSA) in any of those segments predict the development of angiographic ISR at 9 months. In this study, the IVUS-minimal stent area with the lowest ISR and 2-year MACE were $5.0 \mathrm{~mm}^{2}$ for the LCx ostium, $6.3 \mathrm{~mm}^{2}$ for the LAD ostium, $7.2 \mathrm{~mm}^{2}$ for the POC, and $8.2 \mathrm{~mm}^{2}$ for the proximal LM above the POC. UPLM PCI can be approached via varying techniques, either requiring 1-stent or 2-stents. DKCRUSH $\mathrm{V}$ has shown that the 2-stent technique has lower rates of target lesion failure (TLF) at 1 year when compared to single stent technique [18]. While 2-stent techniques had a higher incidence of stent underexpansion when compared to the single stent technique [13], the predictive value of the IVUS areas was independent of the number of stents used. In this series of 400 cases, the most common site of stent underexpansion is the LCx ostia. Therefore, assuring adequate stent area through routine use of imaging is critical to obtaining the best procedural and clinical results in UPLM PCI [34,35]. 


\section{Atherectomy in UPLM PCI}

One of the most important predictors of stent underexpansion in any coronary lesion is the degree of coronary artery calcification [36-38]. Calcium acts to reduce compliance, thus limiting vessel expansion and limiting the effectiveness of balloon dilation, resulting in poor vessel preparation prior to stent deployment [37-39]. Accordingly, PCI in severely calcified lesions is associated with lower success rate, higher complication rates, and poor long-term outcomes when compared to non-calcified lesions $[29,38,40]$. In non-LMCA PCI, the use of atherectomy in calcific coronary disease prior to DES implantation is associated with higher procedural success rates, reduced incidence of ISR, and lower complications $[17,41,42]$. The mechanism of improved lesion compliance after atherectomy is not entirely clear, but it is unlikely that lesion modification is solely related to the volume of plaque removed or ablated.

Utilization of atherectomy in LMCA disease has been reported from several registries. In the ROTATE Registry, a registry of the utilization of rotational atherectomy, LMCA stenosis was the treatment target more commonly in older patients and those with diabetes, when compared to non-LMCA targets [43]. In the DELTA Registry of UPLM PCI, rotational atherectomy was used in $6.1 \%$ of lesions; the use of this technique was a predictor of the primary endpoint of death, MI and CVA (HR 1.73), as well as MACCE (HR 1.87) [44]. In neither of these observational studies were the reasons for use of rotational atherectomy identified, but likely use of this technique was a marker of higher lesion complexity and extensive coronary artery disease. In smaller studies, rotational atherectomy for calcified LMCA was associated with $<20 \%$ TLR at 2 years $[45,46]$. Similarly, first reports of treatment of calcified LMCA stenosis using orbital atherectomy have demonstrated that it is technically feasible with a good short term outcome [14]. IVUS data of the LMCA cases has not been published from any of these atherectomy registries.

Interestingly, debulking of non-calcified LMCA disease has been reported in the bare metal stent era [47]. Directional atherectomy with stenting was associated with lower restenosis rates compared to stenting alone, even though MSA was not significantly larger. The authors hypothesize that residual plaque influenced restenosis, and atherectomy allowed lower residual plaque volumes. Similarly, residual plaque volume has been related to outcome after PCI with DES. Pre-procedural plaque volume as well as residual plaque volume after stent placement [48] are related to clinical outcome after DES, but not minimal stent area. Therefore, in addition to changing compliance in calcified lesions, there may be benefits to debulking beyond altering compliance and achieving the largest stent area.

Future therapies for plaque modification for calcified LMCA disease include coronary lithoplasty, a technique based on lithotripsy for renal calculi, where multiple emitters mounted on a balloon catheter create a diffusive, circumferential, pulsatile mechanical energy that disrupts calcified plaque $[49,50]$. Limited evidence for coronary lithoplasty is available, however optical coherence tomography (OCT) analysis has shown that lithoplasty improves lesion compliance in the presence of severe calcification by creating multiple fractures in single cross sections, which allows for complete stent expansion throughout the entire lesion [50]. The evidence for coronary lithoplasty is still limited and the current studies have not analyzed LMCA lesions. Large, randomized trials are still needed to establish the safety and efficacy of lithoplasty when compared to atherectomy devices, but conceptually this technology is attractive for LMCA disease.

The LMCA was stented with a $3.5 \times 15 \mathrm{~mm}$ Medtronic Resolute Onyx DES (Medtronic, Minneapolis, MN, USA), with proximal optimization performed using a $4.0 \times 8 \mathrm{~mm}$ non-compliant balloon. The CFX was subsequently re-crossed through the LMCA stent struts using the Asahi Sion wire. The CFX was predilated with a $2.5 \mathrm{~mm}$ compliant balloon. The ostial CFX was stented with a $3.0 \times 15 \mathrm{~mm}$ Resolute Onyx DES using a modified T stent technique. Final kissing balloon inflations were performed in the LMCA and CFX with $4.0 \mathrm{~mm}$ and $3.0 \mathrm{~mm}$ noncompliant balloons respectively. A final $40 \mathrm{MHz}$ IVUS was performed, revealing a minimal stent area of $13 \mathrm{~mm}^{2}$ (Figure 3) in the distal LMCA. The angiographic result (Figure 4) was excellent. The patient was seen in outpatient 
follow-up 4 months after UPLM PCI, no episodes of angina or dyspnea on exertion; major issue was mild cognitive impairment.

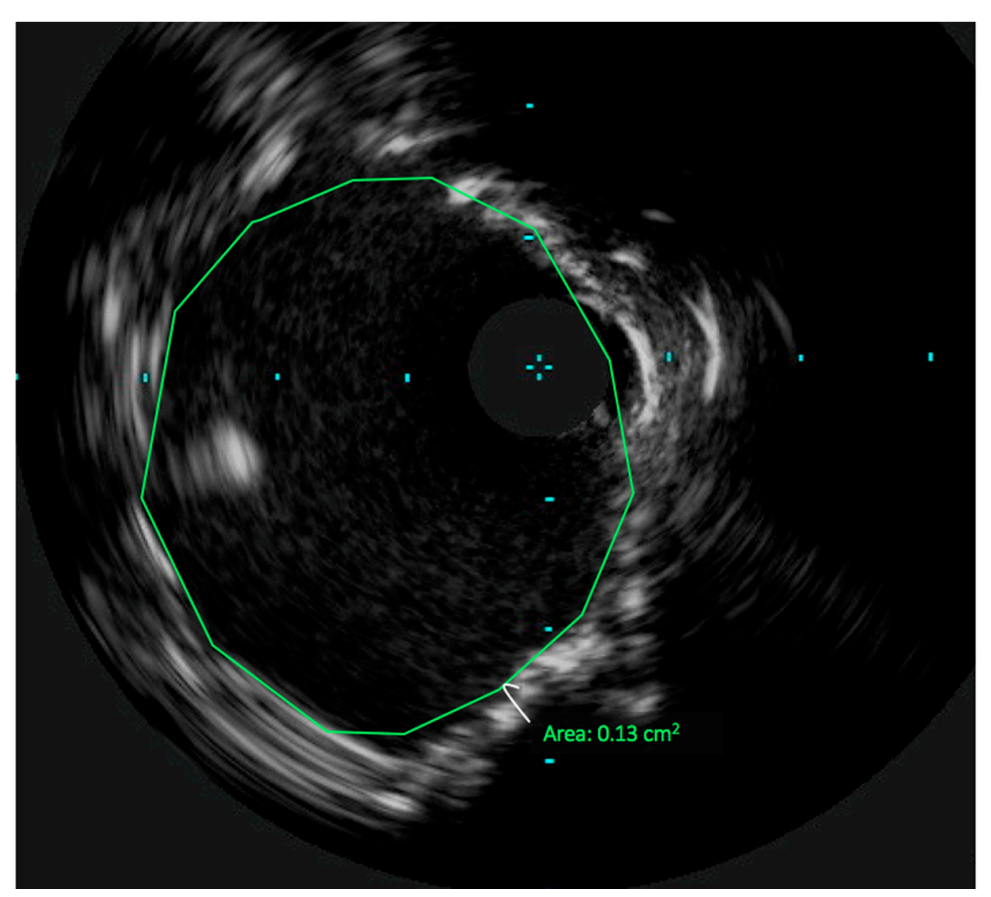

Figure 3. Post-PCI of the LMCA. IVUS of the LMCA after PCI with a $3.5 \times 15 \mathrm{~mm}$ Resolute Onyx DES which dilated with a $4.0 \mathrm{~mm}$ noncompliant balloon. The minimal luminal area measures to $13 \mathrm{~mm}^{2}$. The CFX guidewire is just emerging into the LMCA lumen at 9 o'clock, which suggests that this image is in the distal LMCA. PCI: percutaneous coronary intervention. CFX: Left Circumflex Artery.

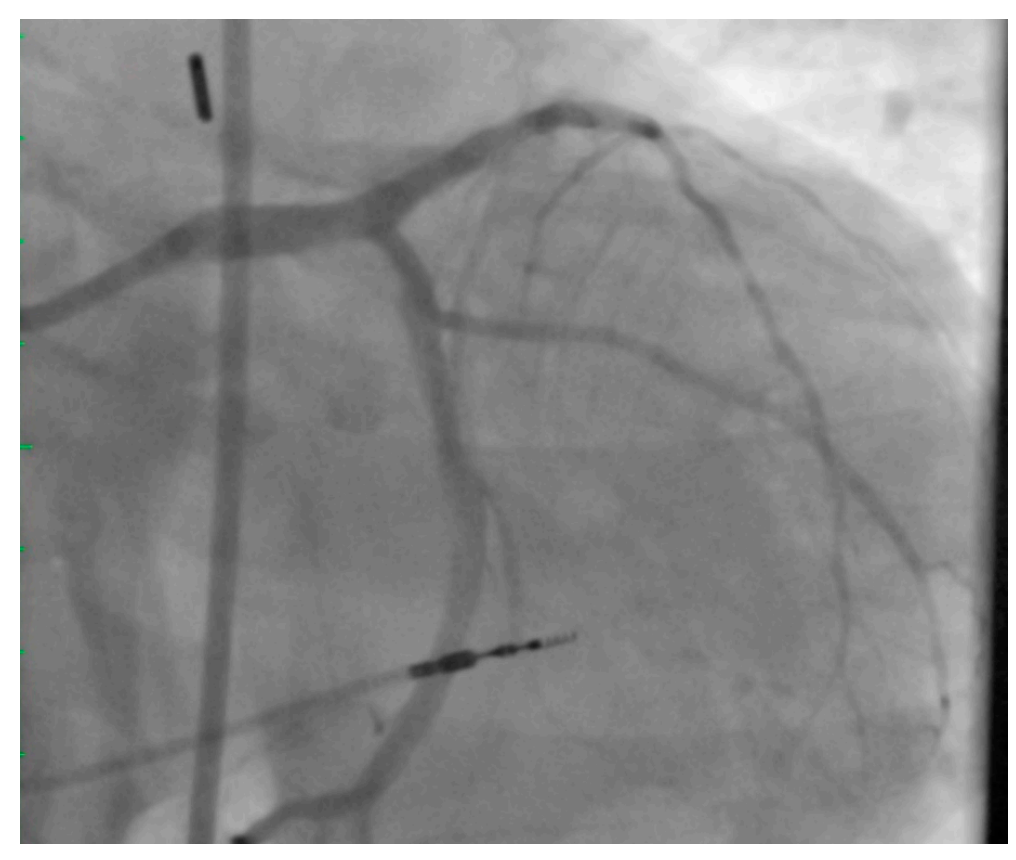

Figure 4. Final Coronary Angiogram. Excellent angiographic result after PCI of the LMCA with a $3.5 \times 15 \mathrm{~mm}$ Resolute Onyx DES, post-dilated with a $4.0 \mathrm{~mm}$ noncompliant balloon. Additionally, PCI of the ostial CFX was completed using a modified T-stent technique with a $3.0 \times 15 \mathrm{~mm}$ Resolute Onyx DES. Final kissing balloon inflations were performed. 


\section{Conclusions}

Durable clinical success in UPLM PCI is dependent on a number of procedural factors. Utilization of IVUS for procedure planning and evaluation of final stent area is established as the standard of care because of associated improved mortality, as well as reduced rates of ISR and stent thrombosis [30]. Two stent techniques, particularly DK Crush, are superior to single stent or provisional strategies. Given that the LMCA stenosis is often characterized by large plaque burden and calcification, a strategy of debulking for plaque modification can contribute to optimal stent expansion and achievement of stent areas that have been related to the best long term outcomes. In addition to endoluminal imaging with IVUS or optical coherence tomography, we believe that atherectomy should be applied more routinely in UPLM PCI.

Author Contributions: C.A.S. and S.E.P. conceived and designed the idea for this paper. C.A.S. and S.E.P. were involved as operators in the patient case. C.A.S. wrote the paper.

Funding: This research received no external funding.

Conflicts of Interest: The authors declare no conflict of interest.

\section{References}

1. Ragosta, M.; Dee, S.; Sarembock, I.J.; Lipson, L.C.; Gimple, L.W.; Powers, E.R. Prevalence of unfavorable angiographic characteristics for percutaneous intervention in patients with unprotected left main coronary artery disease. Catheter. Cardiovasc. Interv. 2006, 68, 357-362. [CrossRef] [PubMed]

2. Grüntzig, A.R.; Senning, A.; Siegenthaler, W.E. Nonoperative DIlation of Coronary-Artery Stenosis. N. Engl. J. Med. 1979, 301, 61-68. [CrossRef] [PubMed]

3. Stone, G.W.; Sabik, J.F.; Serruys, P.W.; Simonton, C.A.; Genereux, P.; Puskas, J.; Kandzari, D.E.; Morice, M.-C.; Lembo, N.; Brown, W.M., III; et al. Everolimus-Eluting Stents or Bypass Surgery for Left Main Coronary Artery Disease. N. Engl. J. Med. 2016, 375, 2223-2235. [CrossRef] [PubMed]

4. Baron, S.J.; Chinnakondepalli, K.; Magnuson, E.A.; Kandzari, D.E.; Puskas, J.D.; Ben-Yehuda, O.; van Es, G.A.; Taggart, D.P.; Morice, M.C.; Lembo, N.J.; et al. Quality of Life after Everolimus-Eluting Stents or Bypass Surgery for Treatment of Left Main Disease. J. Am. Coll. Cardiol. 2017, 70, 3113-3122. [CrossRef] [PubMed]

5. Rab, T.; Sheiban, I.; Louvard, Y.; Sawaya, F.J; Zhang, J.J.; Chen, S.L. Current Interventions for the Left Main Bifurcation. JACC Cardiovasc. Interv. 2017, 10, 849-865. [CrossRef] [PubMed]

6. Sheiban, I.; Moretti, C.; D'Ascenzo, F.; Chieffo, A.; Taha, S.; Connor, S.O.; Chandran, S.; de la Torre Hernández, J.M.; Chen, S.; Varbella, F.; et al. Long-Term ( $>$ /=10 Years) Safety of Percutaneous Treatment of Unprotected Left Main Stenosis With Drug-Eluting Stents. Am. J. Cardiol. 2016, 118, 32-39. [CrossRef] [PubMed]

7. Cavalcante, R.; Sotomi, Y.; Lee, C.W.; Ahn, J.M.; Farooq, V.; Tateishi, H.; Tenekecioglu, E.; Zeng, Y.; Suwannasom, P.; Collet, C.; et al. Outcomes after Percutaneous Coronary Intervention or Bypass Surgery in Patients With Unprotected Left Main Disease. J. Am. Coll. Cardiol. 2016, 68, 999-1009. [CrossRef] [PubMed]

8. Ahn, J.M.; Roh, J.H.; Kim, Y.H.; Park, D.W.; Yun, S.C.; Lee, P.H.; Chang, M.; Park, H.W.; Lee, S.W.; Lee, C.W.; et al. Randomized Trial of Stents Versus Bypass Surgery for Left Main Coronary Artery Disease: 5-Year Outcomes of the PRECOMBAT Study. J. Am. Coll. Cardiol. 2015, 65, 2198-2206. [CrossRef] [PubMed]

9. Park, S.J.; Ahn, J.M.; Kim, Y.H.; Park, D.W.; Yun, S.C.; Yoon, S.H.; Park, H.W.; Chang, M.; Lee, J.Y.; Kang, S.J.; et al. Temporal trends in revascularization strategy and outcomes in left main coronary artery stenosis: Data from the ASAN Medical Center-Left MAIN Revascularization registry. Circ. Cardiovasc. Interv. 2015, 8, e001846. [CrossRef] [PubMed]

10. Migliorini, A.; Valenti, R.; Parodi, G.; Vergara, R.; Buonamici, P.; Cerisano, G.; Carrabba, N.; Antoniucci, D. Angiographic and Clinical Outcomes After Everolimus-Eluting Stenting for Unprotected Left Main Disease and High Anatomic Coronary Complexity. JACC Cardiovasc. Interv. 2016, 9, 1001-1007. [CrossRef] [PubMed]

11. Tamburino, C.; Capranzano, P.; Capodanno, D.; Tagliareni, F.; Biondi-Zoccai, G.; Sanfilippo, A.; Caggegi, A.; Barrano, G.; Monaco, S.; Tomasello, S.D.; et al. Plaque distribution patterns in distal left main coronary artery to predict outcomes after stent implantation. JACC Cardiovasc. Interv. 2010, 3, 624-631. [CrossRef] [PubMed]

12. Lefèvre, T.; Girasis, C.; Lassen, J.F. Differences between the left main and other bifurcations. EuroIntervention 2015, 11. [CrossRef] [PubMed] 
13. Kang, S.J.; Ahn, J.M.; Song, H.; Kim, W.J.; Lee, J.Y.; Park, D.W.; Yun, S.C.; Lee, S.W.; Kim, Y.H.; Lee, C.W.; et al. Comprehensive intravascular ultrasound assessment of stent area and its impact on restenosis and adverse cardiac events in 403 patients with unprotected left main disease. Circ. Cardiovasc. Interv. 2011, 4, 562-569. [CrossRef] [PubMed]

14. Bhatt, P.; Parikh, P.; Patel, A.; Chag, M.; Chandarana, A.; Parikh, R.; Parikh, K. Orbital atherectomy system in treating calcified coronary lesions: 3-Year follow-up in first human use study (ORBIT I. trial). Cardiovasc. Revasc. Med. 2014, 15, 204-208. [CrossRef] [PubMed]

15. Kovach, J.A.; Mintz, G.S.; Pichard, A.D.; Kent, K.M.; Popma, J.J.; Satler, L.F.; Leon, M.B. Sequential intravascular ultrasound of the mechanisms of rotational atherectomy and adjunct balloon angioplasty. J. Am. Coll. Cardiol. 1993, 22, 1024-1032. [CrossRef]

16. Brogan, W.C., III; Popma, J.J.; Mintz, G.S.; Pichard, A.D.; Satler, L.F.; Kent, K.M.; Leon, M.B. Rotational coronary atherectomy after unsuccessful coronary balloon angioplasty. Am. J. Cardiol. 1993, 71, 794-798. [CrossRef]

17. Rathore, S.; Matsuo, H.; Terashima, M.; Kinoshita, Y.; Kimura, M.; Tsuchikane, E.; Nasu, K.; Ehara, M.; Asakura, Y.; Katoh, O.; et al. Rotational atherectomy for fibro-calcific coronary artery disease in drug eluting stent era: Procedural outcomes and angiographic follow-up results. Catheter. Cardiovasc. Interv. 2010, 75, 919-927. [CrossRef] [PubMed]

18. Chen, S.L.; Zhang, J.J.; Han, Y.; Kan, J.; Chen, L.; Qiu, C.; Jiang, T.; Tao, L.; Zeng, H.; Li, L.; et al. Double Kissing Crush Versus Provisional Stenting for Left Main Distal Bifurcation Lesions: DKCRUSH-V Randomized Trial. J. Am. Coll. Cardiol. 2017, 70, 2605-2617. [CrossRef] [PubMed]

19. Taylor, H.A.; Deumite, N.; Chaitman, B.R.; Davis, K.B.; Killip, T.; Rogers, W.J. Asymptomatic left main coronary artery disease in the Coronary Artery Surgery Study (CASS) registry. Circulation 1989, 79, 1171-1179. [CrossRef] [PubMed]

20. De Caterina, A.R.; Cuculi, F.; Banning, A.P. Incidence, predictors and management of left main coronary artery stent restenosis: A comprehensive review in the era of drug-eluting stents. EuroIntervention 2013, 8, 1326-1334. [CrossRef] [PubMed]

21. Fihn, S.D.; Blankenship, J.C.; Alexander, K.P.; Bittl, J.A.; Byrne, J.G.; Fletcher, B.J.; Fonarow, G.C.; Lange, R.A.; Levine, G.N.; Maddox, T.M.; et al. 2014 ACC/AHA/AATS/PCNA/SCAI/STS focused update of the guideline for the diagnosis and management of patients with stable ischemic heart disease: A report of the American College of Cardiology/American Heart Association Task Force on Practice Guidelines, and the American Association for Thoracic Surgery, Preventive Cardiovascular Nurses Association, Society for Cardiovascular Angiography and Interventions, and Society of Thoracic Surgeons. J. Am. Coll. Cardiol. 2014, 64, 1929-1949. [PubMed]

22. Morice, M.C.; Serruys, P.W.; Kappetein, A.P.; Feldman, T.E.; Stahle, E.; Colombo, A.; Mack, M.J.; Holmes, D.R.; Choi, J.W.; Ruzyllo, W.; et al. Five-year outcomes in patients with left main disease treated with either percutaneous coronary intervention or coronary artery bypass grafting in the synergy between percutaneous coronary intervention with taxus and cardiac surgery trial. Circulation 2014, 129, 2388-2394. [CrossRef] [PubMed]

23. Mäkikallio, T.; Holm, N.R.; Lindsay, M.; Spence, M.S.; Erglis, A.; Menown, I.B.; Trovik, T.; Eskola, M.; Romppanen, H.; Kellerth, T.; et al. Percutaneous coronary angioplasty versus coronary artery bypass grafting in treatment of unprotected left main stenosis (NOBLE): A prospective, randomised, open-label, non-inferiority trial. Lancet 2016, 388, 2743-2752. [CrossRef]

24. De Rosa, S.; Sabatino, J.; Indolfi, C. Long-term outcomes of coronary artery bypass grafting versus stent-PCI for unprotected left main disease: A meta-analysis. BMC Cardiovasc. Disord. 2017, 17, 240. [CrossRef] [PubMed]

25. Mohr, F.W.; Morice, M.-C.; Kappetein, A.P.; Feldman, T.E.; Ståhle, E.; Colombo, A.; Mack, M.J.; Holmes, D.R., Jr.; Morel, M.A.; Van Dyck, N.; et al. Coronary artery bypass graft surgery versus percutaneous coronary intervention in patients with three-vessel disease and left main coronary disease: 5-year follow-up of the randomised, clinical SYNTAX trial. Lancet 2013, 381, 629-638. [CrossRef] 
26. De la Torre Hernandez, J.M.; Baz Alonso, J.A.; Gomez Hospital, J.A.; Alfonso Manterola, F.; Garcia Camarero, T.; Gimeno de Carlos, F.; Roura Ferrer, G.; Recalde, A.S.; Martínez-Luengas, I.L.; Gomez Lara, J.; et al. Clinical impact of intravascular ultrasound guidance in drug-eluting stent implantation for unprotected left main coronary disease: Pooled analysis at the patient-level of 4 registries. JACC Cardiovasc. Interv. 2014, 7, $244-254$. [CrossRef] [PubMed]

27. Park, S.J.; Kim, Y.H.; Park, D.W.; Lee, S.W.; Kim, W.J.; Suh, J.; Yun, S.C.; Lee, C.W.; Hong, M.K.; Lee, J.H.; et al. Impact of intravascular ultrasound guidance on long-term mortality in stenting for unprotected left main coronary artery stenosis. Circ. Cardiovasc. Interv. 2009, 2, 167-177. [CrossRef] [PubMed]

28. De la Torre Hernandez, J.M.; Hernandez Hernandez, F.; Alfonso, F.; Rumoroso, J.R.; Lopez-Palop, R.; Sadaba, M.; Carrillo, P.; Rondan, J.; Lozano, I.; Ruiz Nodar, J.M.; et al. Prospective application of pre-defined intravascular ultrasound criteria for assessment of intermediate left main coronary artery lesions results from the multicenter LITRO study. J. Am. Coll. Cardiol. 2011, 58, 351-358. [CrossRef] [PubMed]

29. Mintz, G.S. Intravascular imaging of coronary calcification and its clinical implications. JACC Cardiovasc. Imaging 2015, 8, 461-471. [CrossRef] [PubMed]

30. Tan, Q.; Wang, Q.; Liu, D.; Zhang, S.; Zhang, Y.; Li, Y. Intravascular ultrasound-guided unprotected left main coronary artery stenting in the elderly. Saudi Med. J. 2015, 36, 549-553. [CrossRef] [PubMed]

31. Rogacka, R.; Latib, A.; Colombo, A. IVUS-Guided Stent Implantation to Improve Outcome: A Promise Waiting to be Fulfilled. Curr. Cardiol. Rev. 2009, 5, 78-86. [CrossRef] [PubMed]

32. Fitzgerald, P.J.; Oshima, A.; Hayase, M.; Metz, J.A.; Bailey, S.R.; Cleman, M.W.; Deutsch, E.; Diver, D.J.; Moses, J.W.; Oesterle, S.N.; et al. Final Results of the Can Routine Ultrasound Influence Stent Expansion (CRUISE) Study. Circulation 2000, 102, 523-530. [CrossRef] [PubMed]

33. Hong, S.J.; Kim, B.K.; Shin, D.H.; Nam, C.M.; Kim, J.S.; Ko, Y.G.; Choi, D.; Kang, T.S.; Kang, W.C.; Her, A.Y; et al. Effect of Intravascular Ultrasound-Guided vs Angiography-Guided Everolimus-Eluting Stent Implantation: The IVUS-XPL Randomized Clinical Trial. JAMA 2015, 314, 2155-2163. [CrossRef] [PubMed]

34. Buszman, P.E.; Kiesz, S.R.; Bochenek, A.; Peszek-Przybyla, E.; Szkrobka, I.; Debinski, M.; Bialkowska, B.; Dudek, D.; Gruszka, A.; Zurakowski, A.; et al. Acute and late outcomes of unprotected left main stenting in comparison with surgical revascularization. J. Am. Coll. Cardiol. 2008, 51, 538-545. [CrossRef] [PubMed]

35. Kim, Y.H.; Dangas, G.D.; Solinas, E.; Aoki, J.; Parise, H.; Kimura, M.; Franklin-Bond, T.; Dasgupta, N.K.; Kirtane, A.J.; Moussa, I.; et al. Effectiveness of drug-eluting stent implantation for patients with unprotected left main coronary artery stenosis. Am. J. Cardiol. 2008, 101, 801-806. [CrossRef] [PubMed]

36. Mintz, G.S. Clinical utility of intravascular imaging and physiology in coronary artery disease. J. Am. Coll. Cardiol. 2014, 64, 207-222. [CrossRef] [PubMed]

37. Ellis, S.G.; Roubin, G.S.; King, S.B.; Douglas, J.S., Jr.; Weintraub, W.S.; Thomas, R.G.; Cox, W.R. Angiographic and clinical predictors of acute closure after native vessel coronary angioplasty. Circulation 1988, 77, 372-379. [CrossRef] [PubMed]

38. Wilensky, R.L.; Selzer, F.; Johnston, J.; Laskey, W.K.; Klugherz, B.D.; Block, P.; Cohen, H.; Detre, K.; Williams, D.O. Relation of percutaneous coronary intervention of complex lesions to clinical outcomes (from the NHLBI Dynamic Registry). Am. J. Cardiol. 2002, 90, 216-221. [CrossRef]

39. Attizzani, G.F.; Patricio, L.; Bezerra, H.G. Optical coherence tomography assessment of calcified plaque modification after rotational atherectomy. Catheter. Cardiovasc. Interv. 2013, 81, 558-561. [CrossRef] [PubMed]

40. Chambers, J.W.; Behrens, A.N.; Martinsen, B.J. Atherectomy Devices for the Treatment of Calcified Coronary Lesions. Interv. Cardiol. Clin. 2016, 5, 143-151. [CrossRef] [PubMed]

41. Hoffmann, R.; Mintz, G.S.; Kent, K.M.; Pichard, A.D.; Satler, L.F.; Popma, J.J.; Hong, M.K.; Laird, J.R.; Leon, M.B. Comparative early and nine-month results of rotational atherectomy, stents, and the combination of both for calcified lesions in large coronary arteries. Am. J. Cardiol. 1998, 81, 552-557. [CrossRef]

42. Chiang, M.H.; Lee, W.L.; Tsao, C.R.; Chang, W.C.; Su, C.S.; Liu, T.J.; Liang, K.W.; Ting, C.T. The use and clinical outcomes of rotablation in challenging cases in the drug-eluting stent era. J. Chin. Med. Assoc. 2013, 76, 71-77. [CrossRef] [PubMed]

43. Iannaccone, M.; Barbero, U.; D’Ascenzo, F.; Latib, A.; Pennacchi, M.; Rossi, M.L.; Ugo, F.; Meliga, E.; Kawamoto, H.; Moretti, C.; et al. Rotational atherectomy in very long lesions: Results for the ROTATE registry. Catheter. Cardiovasc. Interv. 2016, 88, E164-E172. [CrossRef] [PubMed] 
44. Chieffo, A.; Meliga, E.; Latib, A.; Park, S.J.; Onuma, Y.; Capranzano, P.; Valgimigli, M.; Jegere, S.; Makkar, R.R.; Palacios, I.F.; et al. Drug-eluting stent for left main coronary artery disease. The DELTA registry: A multicenter registry evaluating percutaneous coronary intervention versus coronary artery bypass grafting for left main treatment. JACC Cardiovasc. Interv. 2012, 5, 718-727. [CrossRef] [PubMed]

45. Garcia-Lara, J.; Pinar, E.; Valdesuso, R.; Lacunza, J.; Gimeno, J.R.; Hurtado, J.A.; Valdés-Chávarri, M. Percutaneous coronary intervention with rotational atherectomy for severely calcified unprotected left main: Immediate and two-years follow-up results. Catheter. Cardiovasc. Interv. 2012, 80, 215-220. [CrossRef] [PubMed]

46. Yabushita, H.; Takagi, K.; Tahara, S.; Fujino, Y.; Warisawa, T.; Kawamoto, H.; Watanabe, Y.; Mitomo, S.; Karube, K.; Matsumoto, T.; et al. Impact of Rotational Atherectomy on Heavily Calcified, Unprotected Left Main Disease. Circ. J. 2014, 78, 1867-1872. [CrossRef] [PubMed]

47. Park, S.-J.; Hong, M.-K.; Lee, C.W.; Kim, J.-J.; Song, J.-K.; Kang, D.-H.; Park, S.-W.; Mintz, G.S. Elective stenting of unprotected left main coronary artery stenosis. J. Am. Coll. Cardiol. 2001, 38, 1054-1060. [CrossRef]

48. Ariyaratne, T.V.; Ademi, Z.; Yap, C.H.; Billah, B.; Rosenfeldt, F.; Yan, B.P.; Reid, C.M. Prolonged effectiveness of coronary artery bypass surgery versus drug-eluting stents in diabetics with multi-vessel disease: An updated systematic review and meta-analysis. Int. J. Cardiol. 2014, 176, 346-353. [CrossRef] [PubMed]

49. Todd, J.; Brinton, M.; Ali, Z.; Mario, C.D.; Maehara, A.; Illindala, U.; Whitbourn, R.; Gotberg, M.; Van Miegham, N.; Hill, J.; et al. DISRUPT CAD: A Multicenter, Prospective, Single-Arm Study of Percutaneous Lithoplastyprior to Stent Implantation in Heavily Calcified Coronary Lesions. Available online: https:/ / www.tctmd.com/slide/disrupt-cad-multicenterprospective-single-arm-studypercutaneouslithoplasty-prior-stent (accessed on 15 April 2018).

50. Ali, Z.A.; Brinton, T.J.; Hill, J.M.; Maehara, A.; Matsumura, M.; Galougahi, K.; Illindala, U.; Götberg, M.; Whitbourn, R.; Van Mieghem, N.; et al. Optical Coherence Tomography Characterization of Coronary Lithoplasty for Treatment of Calcified Lesions: First Description. JACC Cardiovasc. Imaging 2017, 10, 897-906. [CrossRef] [PubMed]

(C) 2018 by the authors. Licensee MDPI, Basel, Switzerland. This article is an open access article distributed under the terms and conditions of the Creative Commons Attribution (CC BY) license (http:/ / creativecommons.org/licenses/by/4.0/). 